\title{
Study of the Discharge Stream from a Standard Rushton turbine impeller
}

J. Kratěna, I. Fořt

The discharge stream from a standard Rushton turbine impeller exhibits special flow properties different from the characteristics of the velocity field in other parts of the volume of an agitated liquid in a cylindrical baffled vessel, e.g. two prevailing components of the mean velocity (radial and tangential), high rate of turbulent energy dissipation and anisotropy of turbulence in this region. At the same time, the discharge stream plays an important role in mixing operations, above all in liquid-liquid and gas-liquid systems.

This paper deals with theoretical and experimental studies of the velocity field and flow of angular momentum in a discharge stream from a standard Rushton turbine impeller in a cylindrical baffled flat bottomed vessel under turbulent regime of flow of an agitated liquid with emphasis on describing the ensemble averaged values over the whole interval of the tangential coordinate around the vessel perimeter.

Keywords: Rushton turbine impeller, discharge stream, turbulent flow, velocity field.

\section{Introduction}

The discharge stream from a standard Rushton turbine impeller exhibits special flow properties different from the characteristics of the velocity field in other parts of the volume of an agitated liquid in a cylindrical baffled vessel [e.g. 1-7] , e.g. prevailing two components of the mean velocity (radial and tangential), a high rate of turbulent energy dissipation and anisotropy of turbulence in this region. At the same time, the discharge stream plays an important role in mixing operations, above all in liquid-liquid and gas-liquid systems [e.g. 10, 11].

This paper deals with a study of the velocity field and flow of the angular momentum in a discharge stream from a standard Rushton turbine impeller in a cylindrical baffled flat bottomed vessel under turbulent regime of flow of an agitated liquid. Three approaches to a description of the discharge stream are used:

1. A theoretical approach, when the impeller discharge stream is modelled as an axially symmetrical tangential submerged jet.

2. An experimental approach, i.e. determination of the force interaction of the impeller discharge stream and radial baffles by means of the trailing target.

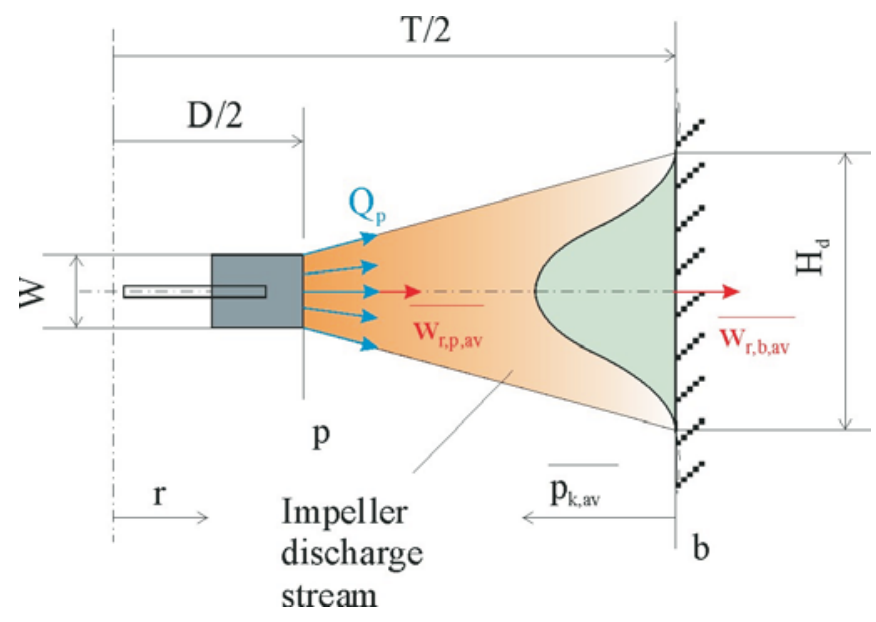

Fig. 1: Vertical view of the Rushton impeller discharge stream
3. A numerical simulation of the turbulent liquid flow in the whole agitated system with emphasis on the impeller discharge stream.

\section{Theoretical}

Let us consider a flat-bottomed cylindrical vessel with four baffles at its wall. In the vessel the standard Rushton turbine impeller [12] is coaxially located and rotates under turbulent regime of flow of an agitated liquid. In the region of the radially-tangential impeller discharge stream (see Fig. 1) we assume a constant angular momentum flow between the impeller and the baffle $[1,8]$

$$
\overline{M_{b, d, t h}}=\rho Q_{b}(T / 2) \overline{w_{t, b, a v}}=\rho Q_{p}(D / 2) \overline{w_{t, p, a v}} .
$$

Here index " $p$ " denotes a velocity field near the impeller and index " $b$ " a velocity field near the baffle. Looking at the relation between the radial component of the mean velocity averaged over the impeller discharge stream $\overline{w_{r, p, a v}}$ and the impeller pumping capacity

$$
Q_{p}=\overline{w_{r, p, a v}} \pi D W
$$

and the relation between this component and the tangential one (see Fig. 2)

$$
\overline{w_{t, p, a v}}=\overline{w_{r, p, a v}} \operatorname{tg} \alpha,
$$

where

$$
\alpha=\arcsin [a /(D / 2)],
$$

we can rearrange Eq. 1 into the form

$$
\overline{M_{b, d, t h}}=\rho Q_{p}^{2} \frac{\operatorname{tg}\{\arcsin [a /(D / 2)]\}}{2 \pi W} .
$$

After introduction of the flow rate number (dimensionless impeller pumping capacity)

$$
N_{Q_{p}}=\frac{Q_{p}}{N D^{3}},
$$

where symbol $N$ denotes the impeller speed, we have finally an equation in dimensionless form for the angular momentum flow between the rotating standard Rushton impeller and the vessel wall 


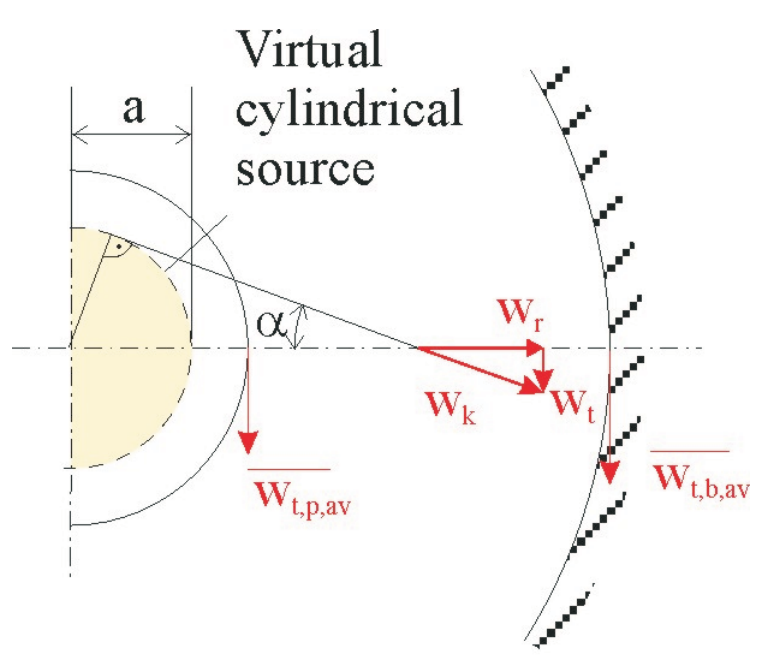

Fig. 2: Turbine impeller as an axially symmetrical tangential source

$$
\overline{M_{b, d, t h}^{*}}=\frac{\overline{M_{b, d, t h}}}{\rho N^{2} D^{5}}=N_{Q_{p}}^{2} \frac{\operatorname{tg}[\arcsin (2 a / D)]}{2 \pi(W / D)} .
$$

Quantity $a$ denotes the radius of the virtual cylindrical source of the impeller discharge stream (see Fig. 2), and for the chosen geometry of the agitated system (see Fig. 3) it holds [1]

$$
2 a / D=0.34
$$

\section{Results of experiments}

Experiments were carried out in a flat-bottomed cylindrical pilot plant mixing vessel with four baffles at its wall (see Fig. 3) of diameter $T=0.3$ filled with either water $(\mu=1 \mathrm{mPa} \cdot \mathrm{s})$ or with one of two water glycerol solutions of $\mathrm{dy}-$ namic viscosity $\mu=3 \mathrm{mPa} \cdot \mathrm{s}$ and $\mu=6 \mathrm{mPa} \cdot \mathrm{s}$, respectively. The impeller was a standard Rushton disk impeller with six flat plate blades [12]. The range of frequency of revolution of the impeller was chosen in the interval $N=3.11-5.83 \mathrm{~s}^{-1}$, so the regime of flow of the agitated liquid was always turbulent.

In order to determine the axial (vertical) distribution of dynamic pressure $p_{d}$ affecting the baffle [9], one of the baffles was equipped with a trailing target (see Fig. 3) of height $h_{T}$ and width $B$ enabling it to be rotated parallel to the vessel axis with a small eccentricity and balanced by springs. Eleven positions of the target along the height of the baffle were examined, above all in the region of the interference of the baffles and the impeller discharge stream. The angular displacement of target $\beta$ is directly proportional to the peripheral component of force $F$ affecting the balancing springs (see Fig. 4). The flexibility of the springs was selected so that the maximum target displacement was reasonably small compared with the vessel dimensions (no more than $0.5 \%$ of the vessel perimeter). A small photoelectronic device composed of two photodiodes scanned the angular displacement, and the output signal was treated, stored and analysed by the computer.

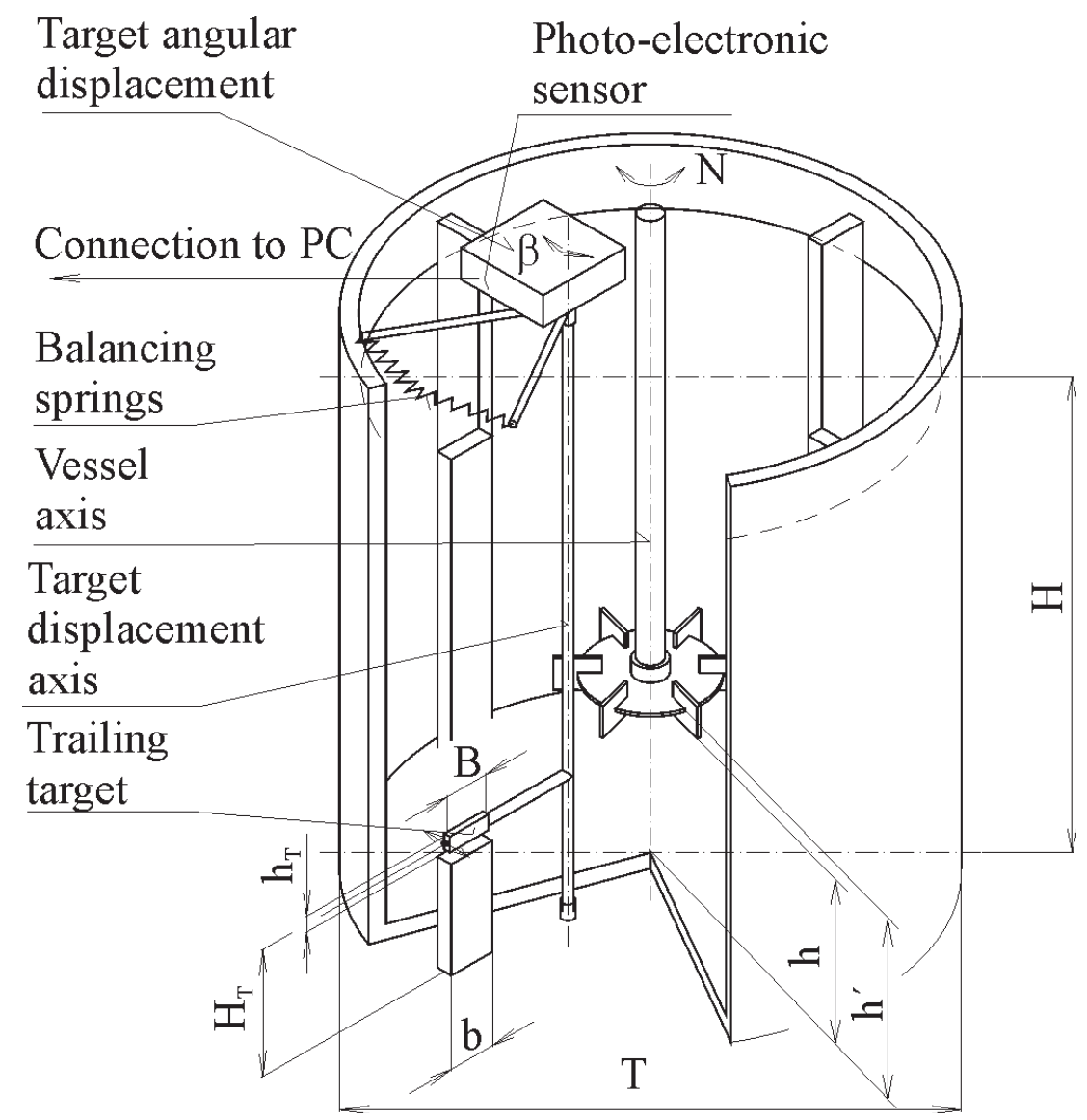

Fig. 3: Sketch of a flat-bottomed agitated pilot plant mixing vessel with four radial baffles at the wall and an axially located standard Rushton impeller and sketch of measurement of local peripheral force affecting the trailing target $(H / T=1, h / T=0.33,0.48$, $\left.b / T=0.1, h_{T}=10 \mathrm{~mm}, B=28 \mathrm{~mm}\right)$ 




Fig. 4: Results of mechanical calibration of balancing springs

The average value of the dimensionless mean dynamic pressure affecting the part of the baffle of dimensionless height $H_{d}^{*}$, i.e. the height of the region of the impeller discharge stream interference with the baffle (see Fig. 5), can be calculated from the relation

$$
\overline{p_{d, a v}^{*}}=\frac{1}{H_{d}^{*}} \int_{H_{b_{1}}^{*}}^{H_{b_{2}}^{*}} \overline{p_{k, a v}^{*}}\left(H_{T} / H\right) \mathrm{d}\left(H_{T} / H\right),
$$
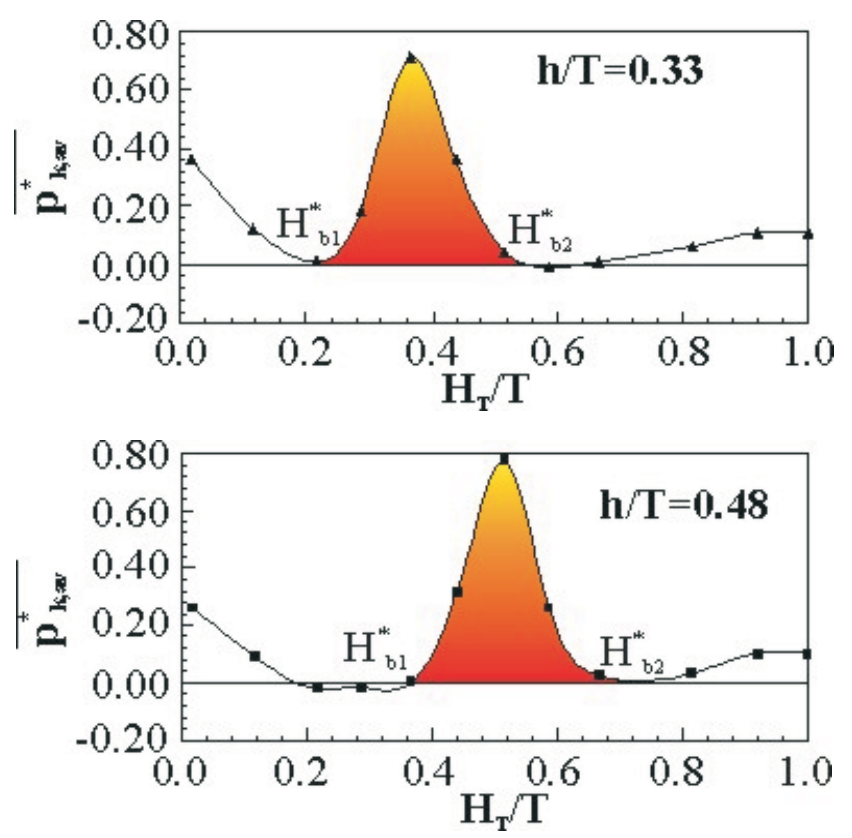

Fig. 5: Axial profile of the dimensionless peripheral component of dynamic pressure affecting radial baffle along its height (shadow part characterizes an interference region of the impeller discharge stream and radial baffle) where

$$
H_{d}^{*}=H_{b_{2}}^{*}-H_{b_{1}}^{*} .
$$

The total dimensionless component of the mean peripheral force affecting the baffle along its interference region with the impeller discharge stream is

$$
\overline{F_{d, a v}^{*}}=\frac{\overline{F_{d, a v}}}{\rho N^{2} D^{4}}=(T / D)^{2} b^{*} H_{d}^{*} \overline{p_{d, a v}^{*}},
$$

where the dimensionless width of baffle

$$
b^{*}=b / T \text {. }
$$

Finally a portion of the dimensionless mean reaction moment of the baffles corresponding to the mutual interference of $n_{b}$ baffles and the impeller discharge stream

$$
\overline{M_{b, d}^{*}}=n_{b} \overline{F_{d, a v}^{*}}\left(R_{b} / D\right)
$$

where the radial coordinate of the centre of gravity of the trailing target [9]

$$
R_{b}=(T / 2)-(2 / 3) b .
$$

Table 1 consists of both theoretical and experimental results of the impeller torque by radial baffles in the discharge stream of the Rushton turbine impeller. It follows from this Table that for both investigated impeller off-bottom clearances $h / T$ theoretical results fit the experimental results fairly well.

Table 1: Transfer of the impeller torque by radial baffles in the discharge flow of a Rushton turbine impeller

\begin{tabular}{|c|c|c|c|c|}
\hline$h / T$ & $H_{d}^{*}$ & $\overline{M_{b, d}^{*}}$ & $\overline{M_{b, d, t h}^{*}}$ & $N_{Q_{p}}[1]$ \\
\hline 0.33 & 0.33 & 0.464 & 0.472 & 0.80 \\
\hline 0.48 & 0.30 & 0.475 & 0.472 & 0.80 \\
\hline
\end{tabular}




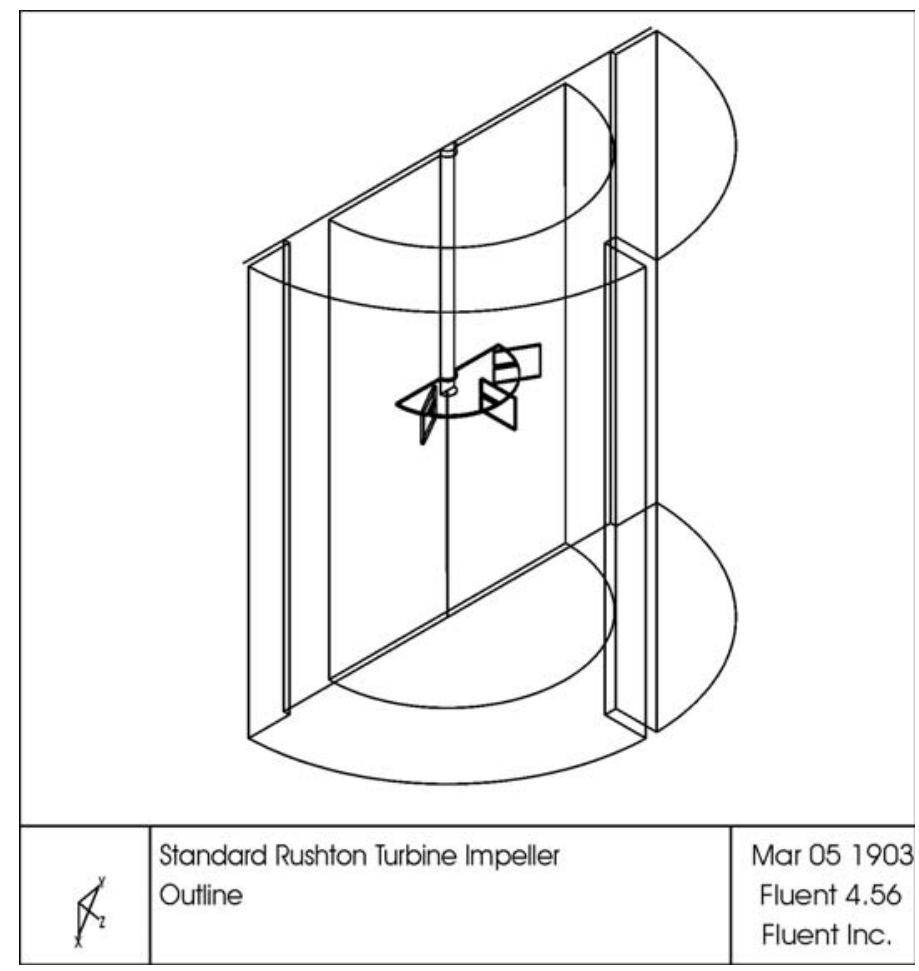

Fig. 6: Three dimensional view of the flat bottomed agitated system with standard Rushton turbine impeller and radial baffles $\left(T=300 \mathrm{~mm}, H / T=1, D / T=1 / 3, h / T=0.33,0.48, b / T=0.1, N=6.7 \mathrm{~s}^{-1}\right)$

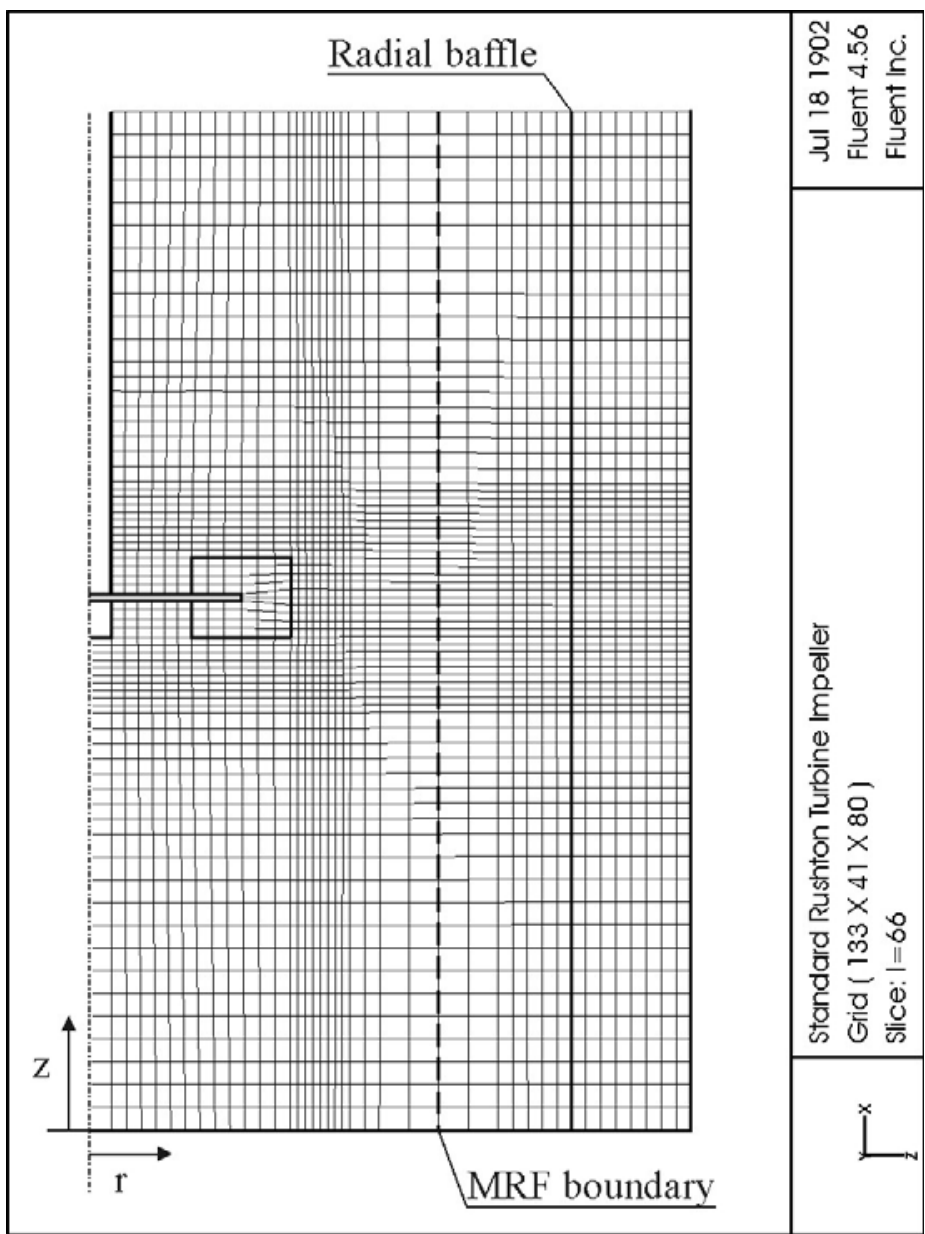

Fig. 7: Side view (coordinates $r-z$ ) of the half of investigated system with chosen grid 


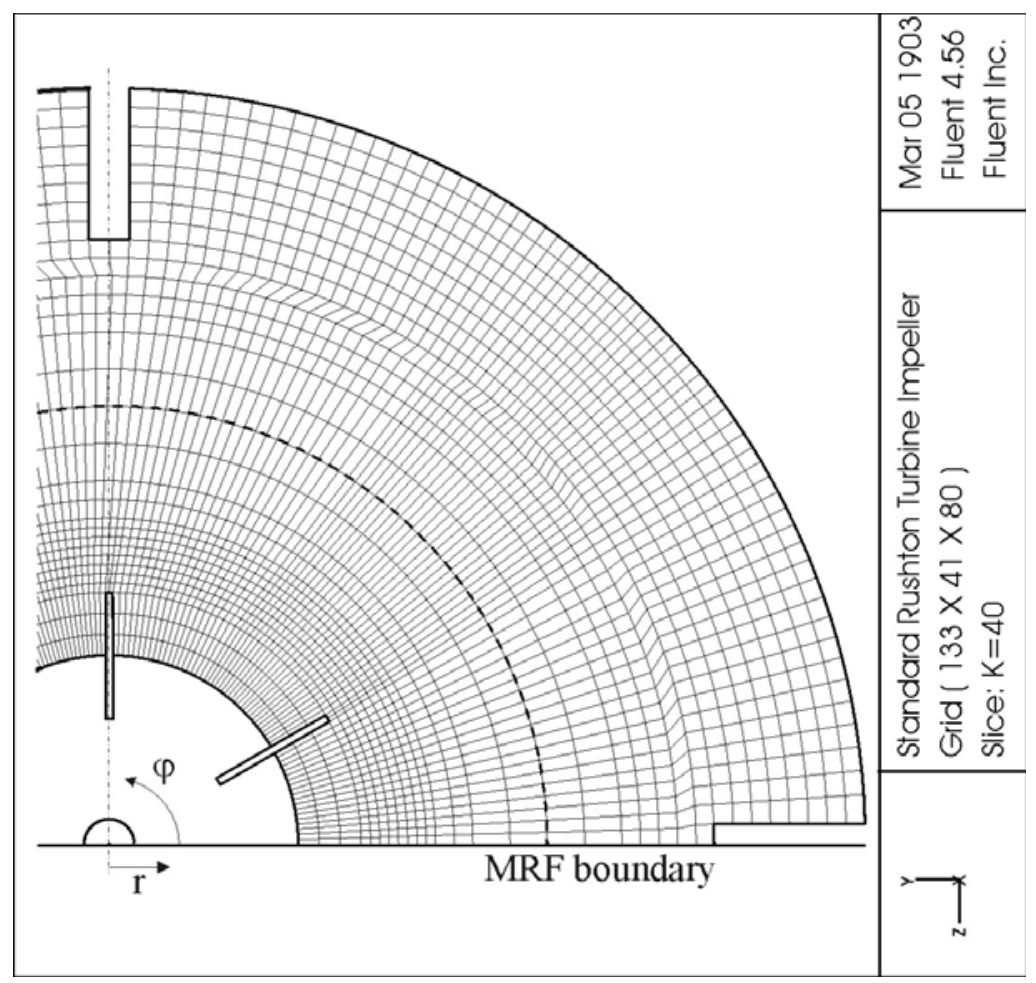

Fig. 8: Top view (coordinates $\varphi-z$ ) of the half of investigated system with chosen grid

\section{Numerical simulation of turbulent liquid flow in a system with a standard Rushton impeller}

Reynolds averaged Navier-Stokes equations (RANS) together with the Multiple Reference Frame (MRF) and standard $k-\varepsilon$ model predictions of steady state flow have been used via Fluent 4.5 commercial software with the MIX SIM 1.7 module [13].

Half of the cylindrical tank with three radial baffles and three impeller blades was modelled (see Fig. 6). The total number of cells in the investigated volume (tangential $\times$ radial $\times$ axial coordinates) was

$$
\begin{array}{ccccc}
\varphi & \times & \times & \times \\
134 & \times & 42 & \times & 81=4.56 \times 10^{5} \text { cells. }
\end{array}
$$

Special attention was paid to selection of the grid density. The highest density of the grid was located in the volume of the maximum level of the rate of turbulent energy dissipation $\varepsilon$ in the impeller discharge stream. On the other hand, the coarsest grid was located in the other volume, i.e. in the remaining volume of the agitated liquid. Figs. 7 and 8 illustrate the selected distribution of the grid a both the $\varphi-r$ and $r-z$ planes.

For the investigated agitated system the following boundary conditions were defined:

1. Vessel wall, baffles and flat bottom - flow in the vicinity of the solid flat plate (laminar sublayer, buffer layer).

2. Liquid surface and cylindrical vessel axis of symmetry - no penetration of liquid through the boundary (batch system).

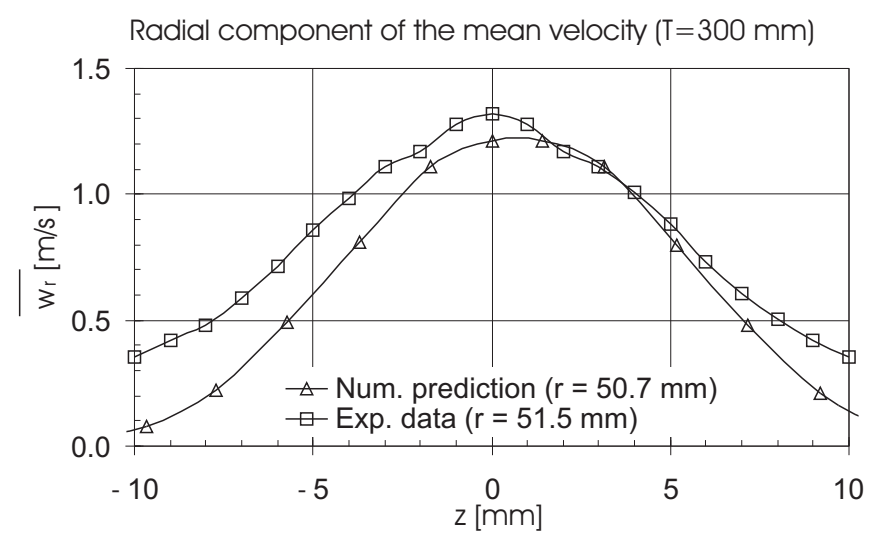

Tangential component of the mean velocity $(T=300 \mathrm{~mm})$

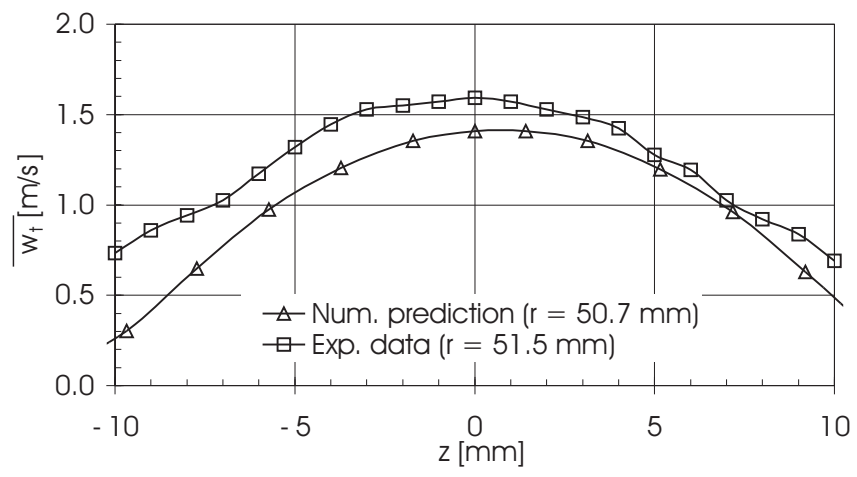

Fig. 9: Comparison of experimentally determined and numerically predicted axial profiles of the radial and tangential components of the mean velocity in the Rushton turbine impeller discharge stream (Exp. Data: Möckel [2]) 


\subsection{Numerical simulation versus experimental data}

The results of numerical prediction of the velocity field in the Rushton turbine discharge stream were compared with the experimental data of Möckel [2] (see Fig. 9). Both axial (vertical) profiles are located right next to the rotating impeller, and in accordance with the experimental technique of Möckel (CTA) they are expressed as the assemble averaged values over the whole circle, i.e. over the internal of tangential coordinate $\varphi \in\left\langle 0^{\circ} ; 360^{\circ}\right\rangle$. It follows from the two compared profiles that the results of the numerical simulation correspond fairly well with the experimental data, but a certain shift of the numerical prediction appears, probably caused by the asymmetrical position of the impeller along the axial coordinate $z$.

Figs. 10 and 11 describe the radial distribution of the tangential component of the mean velocity in the turbine impeller discharge flow for the two investigated off-bottom clearances $h / T$ calculated numerically. This is a very good recognition of the concept of the turbine impeller discharge flow as a turbulent submerged jet. The asymmetrical shape of this jet at the impeller off-bottom clearance $h / T=0.33$ corre- sponds to the above mentioned results, illustrated in Fig. 9. The boundaries of the jet in Figs. 10 and 11 correspond to the value of the given component of the mean velocity amounting to $1 \%$ of its maximum value on the investigated axial profile. The radial profile of the dimensionless volumetric flow rate $Q / N D^{3}$ in the impeller discharge stream plotted in Fig. 12 confirms the above mentioned idea of the submerged jet, because the volumetric flow rate $Q$ increases with increasing radial distance (radial coordinate) from the body of the rotating impeller. Moreover, this figure again exhibits good agreement between the data calculated from numerical simulation of the flow in the investigated system and the available experimental data.

\subsection{Numerical simulation versus theoretical approach}

The predicted axial profiles of the radial and tangential components of the mean velocity in the turbine impeller discharge stream were used in order to calculate of the radial distribution of the angular momentum flow in the investigated region of an agitated system:

$\overline{M_{d, \text { num }}(r)}=\rho Q_{d, \text { num }}(r) r \overline{w_{t, \text { num,av }}(r)}, r \in\langle D / 2 ; T / 2-b\rangle,(15)$

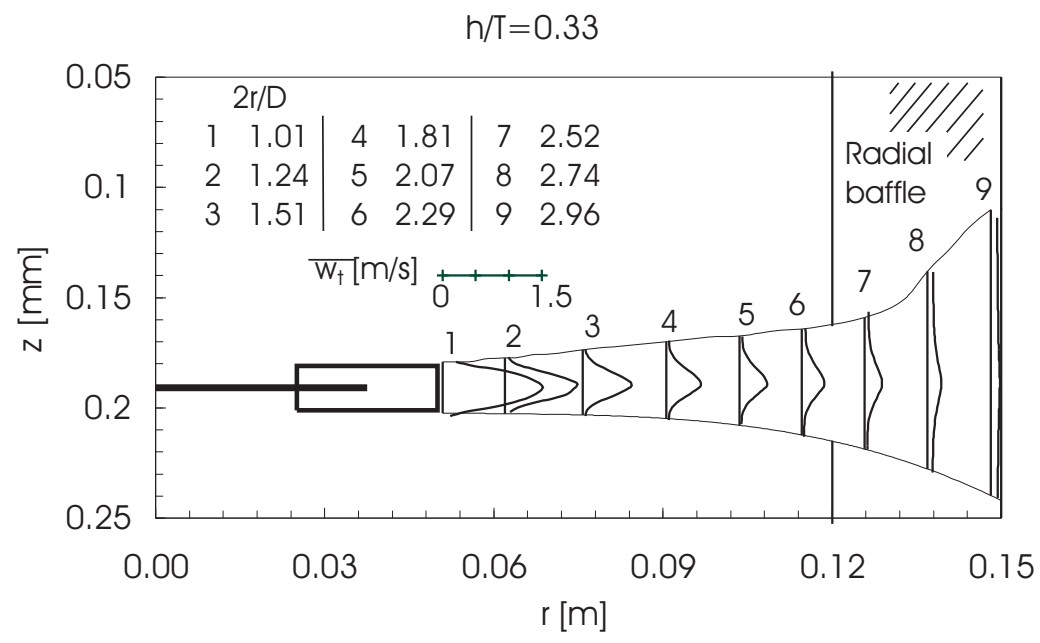

Fig. 10: Radial distribution of tangential component of the mean velocity in the Rushton turbine impeller discharge stream (numerical prediction of ensemble average values over interval of the values of tangential coordinate $\varphi=\left\langle 0^{\circ} ; 360^{\circ}\right\rangle, h / T=0.3$ )

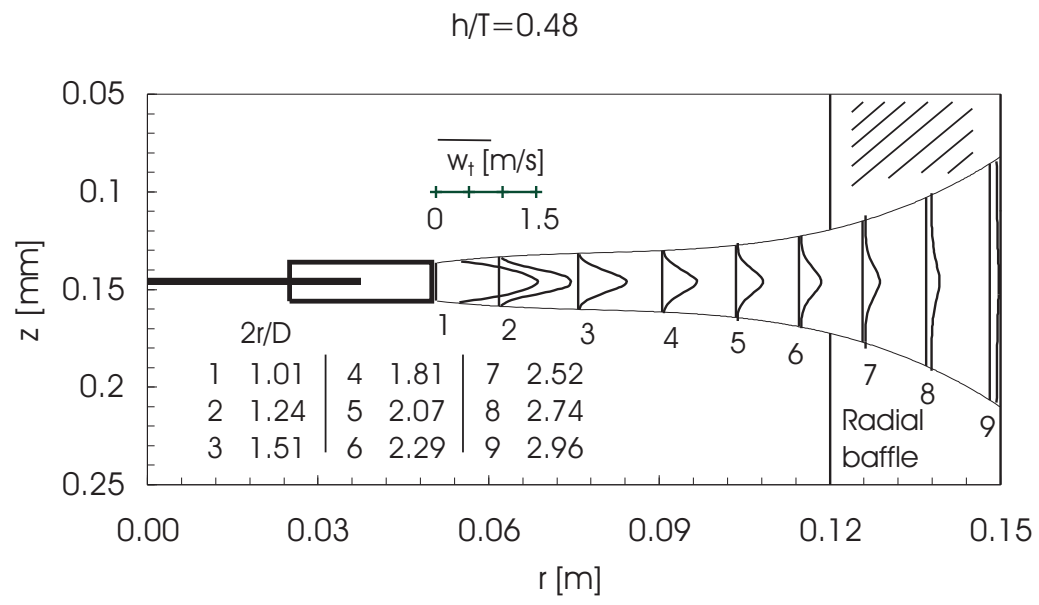

Fig. 11: Radial distribution of tangential component of the mean velocity in the Rushton turbine impeller discharge stream (numerical prediction of ensemble average values over interval of the values of tangential coordinate $\varphi=\left\langle 0^{\circ} ; 360^{\circ}\right\rangle, h / T=0.48$ ) 


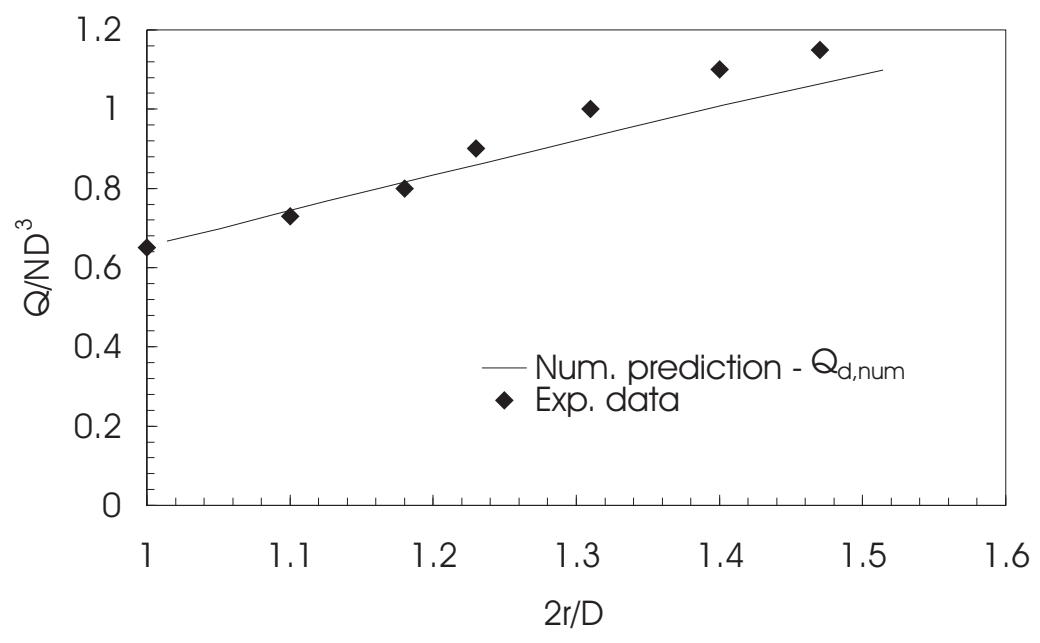

Fig. 12: Radial profile of the dimensionless volumetric flow rate $Q / N D^{3}$ in the Rushton turbine impeller discharge stream $(h / T=0.48$, $D / T=1 / 3$, Exp. Data: Stoots and Calabrese [4])

where the tangential component of the mean velocity averaged over the width of the submerged jet $\left(z_{2}-z_{1}\right)$ at radius $r$ is

$\overline{w_{t, \text { num, av }}(r=\text { const. })}=\frac{1}{z_{2}-z_{1}} \int_{z_{1}}^{z_{2}} \overline{w_{t, \text { num }}(z)} \mathrm{d} z, \quad r=$ const.

Similarly, the local value of the flow rate in the turbine impeller discharge flow can be calculated from the relation

$Q_{d, \text { num }}(r=$ const. $)=2 \pi r \int_{z_{1}}^{z_{2}} \overline{w_{t, \text { num }}(z)} \mathrm{d} z, \quad r=$ const.

Finally Eq. (15) can be expressed in dimensionless form

$\overline{M_{d, \text { nuт }}^{*}(r)}=\frac{\overline{M_{d, \text { nuт }}(r)}}{\rho N^{2} D^{5}}=\frac{Q_{d, \text { nuт }}(r)}{N D^{3}} \frac{\overline{w_{t, \text { num, }, \text { }}(r) r}}{N D^{2}}$.

Figures 13 and 14 presents the results of two compared methods for calculating the angular momentum flow in an investigated turbine impeller discharge flow: a theoretical method (solid line in each figure) and a numerically predicted method (points). It is clearly shown that, although the value of the angular flow momentum in the impeller discharge flow oscillates slightly around its theoretical value, the numerically calculated values $\left(\overline{M_{d, n u m, a v}^{*}}\right)$ and the theoretically predicted values $\overline{\left(M_{d, t h}^{*}\right)}$ agree very well. Moreover, it follows from Table 1 that the values of this quantity determined experimentally differ from the above mentioned values within the range of experimental accuracy.

\section{Conclusions}

The results of the study confirm the idea of the impeller discharge flow of a Rushton turbine as a submerged turbulent jet, where under turbulent regime of flow the angular momentum flow exhibits a practically constant value and its value fits fairly well with the results of the theoretical approach and also the results of experiments.

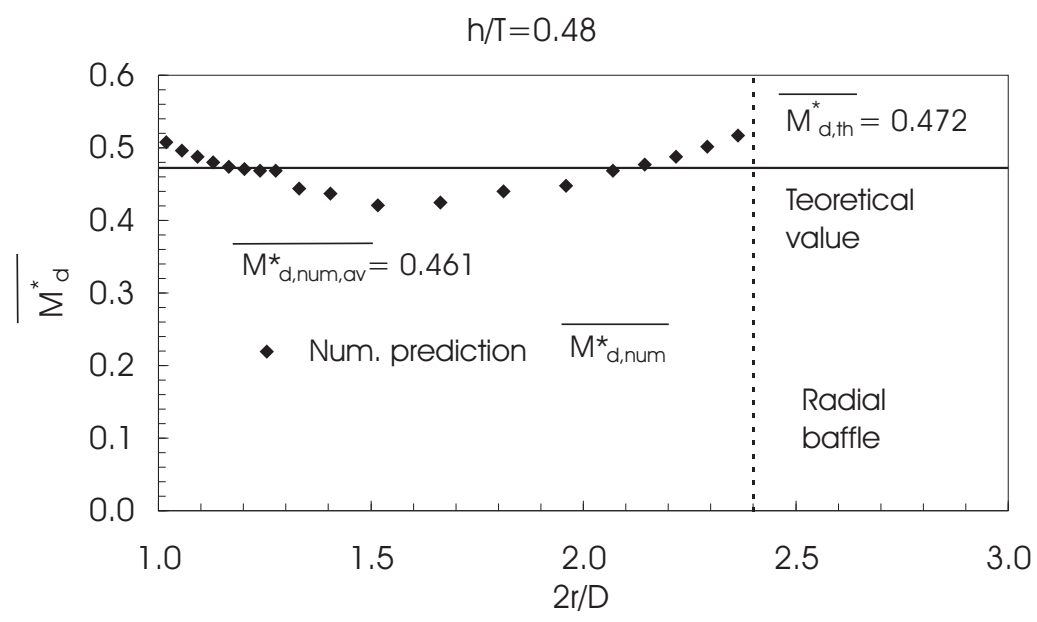

Fig. 13: Radial profile of the angular momentum flow in the Rushton turbine impeller discharge stream in dimensionless form $(h / T=$ $0.33)$ 


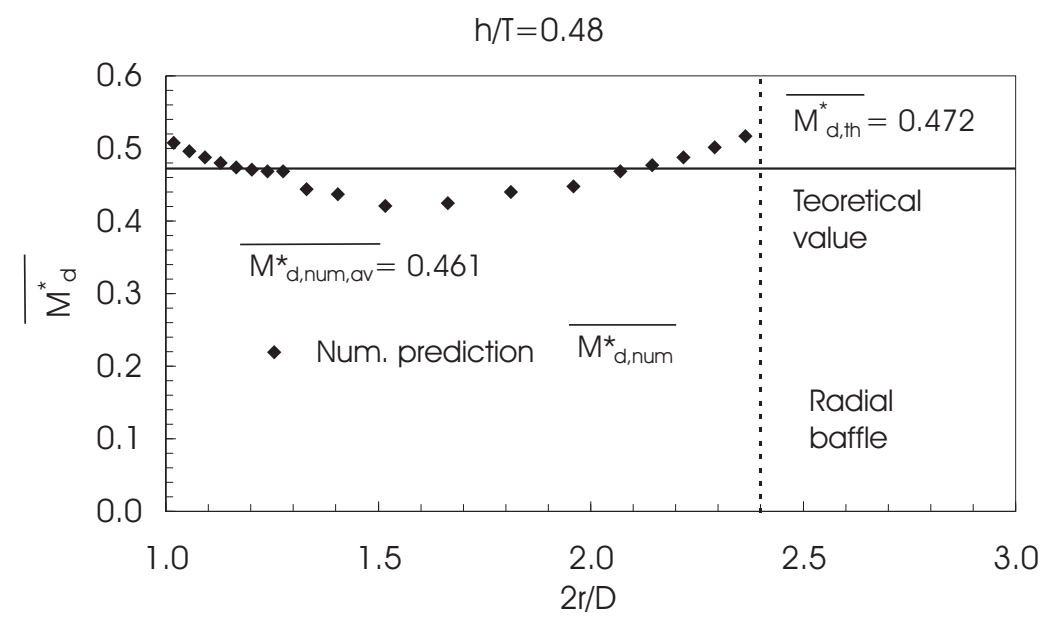

Fig. 14: Radial profile of the angular momentum flow in the Rushton turbine impeller discharge stream in dimensionless form $(h / T=$ $0.48)$

\section{List of Symbols}

radius of the virtual cylindrical source of the impeller discharge stream, $[\mathrm{m}]$

$B$ target width, [m]

$b \quad$ baffle width, [m]

$D$ impeller diameter, $[\mathrm{m}]$

$F \quad$ peripheral component of the force, [N]

$H \quad$ total liquid depth, [m]

$H_{d} \quad$ height of the region of the impeller discharge stream interference with the baffle, [m]

$H_{T} \quad$ height of the target above the bottom, [m]

$h \quad$ impeller off-bottom clearance, [m]

$h_{T} \quad$ target height, [m]

$M \quad$ impeller torque, $[\mathrm{N} \cdot \mathrm{m}]$

$N \quad$ impeller speed, $\left[\mathrm{s}^{-1}\right]$

$N_{Q_{p}} \quad$ flow rate number

$n_{b} \quad$ number of baffles

$Q_{p} \quad$ impeller pumping capacity (impeller flow rate), $\left[\mathrm{m}^{3} \mathrm{~s}^{-1}\right]$

$p \quad$ dynamic pressure, $[\mathrm{Pa}]$

$R_{b} \quad$ radial coordinate of the centre of gravity of the trailing target, [m] radial coordinate, $[\mathrm{m}]$

vessel diameter, $[\mathrm{m}]$

$W \quad$ width of impeller blade, $[\mathrm{m}]$

$w \quad$ liquid local instantaneous velocity, $\left[\mathrm{m} \cdot \mathrm{s}^{-1}\right]$

$z \quad$ axial (vertical) coordinate, $[\mathrm{m}]$

$\alpha \quad$ declination of liquid velocity in the impeller discharge stream from radial coordinate, $\left[{ }^{\circ}\right]$

$\beta \quad$ target angular displacement, $\left[{ }^{\circ}\right]$

$\varphi \quad$ tangential coordinate, $\left[{ }^{\circ}\right]$

$\rho \quad$ density of agitated liquid, $\left[\mathrm{kg} \cdot \mathrm{m}^{-3}\right]$

$\mu \quad$ dynamic viscosity agitated liquid, [Pa-s]

\section{Subscripts and superscripts}

av average value

$b \quad$ related to the region of radial baffles

$d \quad$ related to the volume of the impeller discharge stream

num calculated numerically

$p \quad$ related to the impeller

$r \quad$ radial

$t$ tangential

th theoretical value

z axial (vertical)

* dimensionless value

mean (time averaged) value

\section{Acknowledgment}

This research has been supported by Research Project of the Ministry of Education of the Czech Republic No. J 04/98: 212200008.

\section{References}

[1] Drbohlav J., Fořt I., Krátký, J.: "Turbine impeller as a tangential cylindrical jet." Collect. Czech. Chem. Commun., Vol. 43 (1978), p. 696-712.

[2] Möckel H. O.: Hydrodynamische Untersuchungen in Rührmaschine. Ph.D. Thesis, Ingenieurhochschule Köthen, Dresden (Germany), 1978.

[3] Yianneskis M., Popiolek Z., Whitelaw J. M.: “An experimental study of the steady and unsteady flow characteristics of stirred reactors." J. Fluid. Mech., Vol. 175 (1987), p. 537-555.

[4] Stoots C. M., Calabrese R. V.: "Mean velocity relative to a Rushton turbine blade.” AICHEJ., Vol. 41 (1995), No. 1, p. 1-11.

[5] Rutheford K., Mahmoudi S. M. S., Lee K., Yianneskis, M.: "The influence of a Rushton impeller blade and disk thickness on the mixing characteristics of stirred vessel." 
Trans. Inst. Chem. Engrs., Vol. 74 (1996) (part A), p. 369-378.

[6] Schäfer M., Höfken M., Durst F.: "Detailed LDV measurements for visualization of the flow field within a stirred-tank reactor equipped with a Rushton turbine." Trans. Inst. Chem. Engrs., Vol. 75 (1997) (part A), p. 729-736.

[7] Nikiforaki L., Montante G., Lee K.C., Yianneskis Y.: "On the origin frequency and magnitute of macro-instabilities of the flows in stirred vessels." Chem. Eng. Sci., Vol. 58 (2003), p. 2937-2949.

[8] Bittins K., Zehner P.: "Power and discharge numbers of radial-flow impellers. Fluid dynamic interactions between impeller and baffles." Chem. Eng. and Proc., Vol. 33 (1994), p. 295-301.

[9] Kratěna J., Fořt I., Brůha O., Pavel J.: "Distribution of dynamic pressure along a radial baffle in an agitated system with standard Rushton turbine impeller." Trans. Inst. Chem. Engrs., Vol. 79 (2001) (part A), p. 819-823.

[10] Riet van't K., Smith J. M.: "The behaviour of gas-liquid mixtures near Rushton turbine blades." Chem. Eng. Sci., Vol. 28 (1973), p. 1031-1037.
[11] Wu H., Patterson G. K., Doorn van M.: "Distribution of turbulence energy dissipation rates in a Rushton turbine stirred mixer." Exp. in Fluids, Vol. 8 (1989), p. 153-160.

[12] Turbine disk impeller with flat plate blade, 1997, Czech Standard CVS 691021, Mixing Equipment (Brno).

[13] Fluent 4.5 Users Quide, Fluent Inc., Lebanon (NH, USA), 1997.

Ing.Jiř́i Kratěna
e-mail: kratena@student.fsid.cvut.cz

Doc. Ing. Ivan Fořt, DrSc.

phone: +420224352713

fax: +420224310292

e-mail: fort@fsid.cvut.cz

Dept. of Process Engineering

Czech Technical University in Prague

Faculty of Mechanical Engineering

Technická 4

16607 Praha 6, Czech Republic 